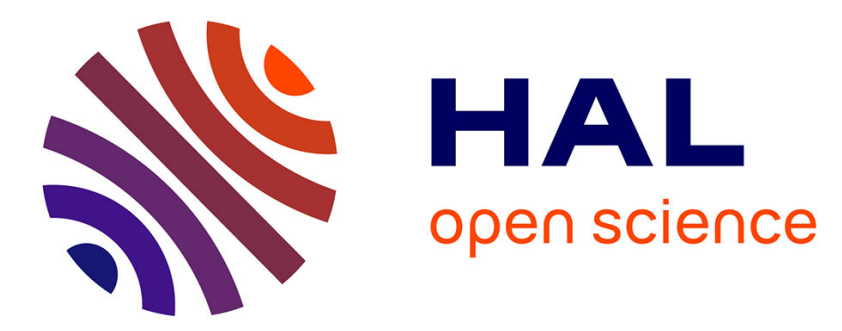

\title{
DETERMINATION OF AN HCF CRITERION BY THERMAL MEASUREMENTS UNDER BIAXIAL CYCLIC LOADING
}

Cédric Doudard, Martin Poncelet, Sylvain Calloch, Christine Boué, François Hild, André Galtier

\section{To cite this version:}

Cédric Doudard, Martin Poncelet, Sylvain Calloch, Christine Boué, François Hild, et al.. DETERMINATION OF AN HCF CRITERION BY THERMAL MEASUREMENTS UNDER BIAXIAL CYCLIC LOADING. International Journal of Fatigue, 2007, 29, pp.748-757. 10.1016/j.ijfatigue.2006.06.009 . hal-00322198

\section{HAL Id: hal-00322198 https://hal.science/hal-00322198}

Submitted on 16 Sep 2008

HAL is a multi-disciplinary open access archive for the deposit and dissemination of scientific research documents, whether they are published or not. The documents may come from teaching and research institutions in France or abroad, or from public or private research centers.
L'archive ouverte pluridisciplinaire HAL, est destinée au dépôt et à la diffusion de documents scientifiques de niveau recherche, publiés ou non, émanant des établissements d'enseignement et de recherche français ou étrangers, des laboratoires publics ou privés. 
Submitted to the International Journal of Fatigue, June 2005

Revised, May 2006

\title{
DETERMINATION OF AN HCF CRITERION
}

BY THERMAL MEASUREMENTS UNDER BIAXIAL CYCLIC LOADING

\author{
C. DOUDARD,,${ }^{* * * 1}$ M. PONCELET, ${ }^{*}$ S. CALLOCH,,${ }^{* * *}$ C. BOUE, ${ }^{* * *}$ F. HILD \\ and A. GALTIER ${ }^{* * * *}$
}
*LMT-Cachan, ENS de Cachan/CNRS-UMR 8535/Université Paris 6 61 avenue du Président Wilson, F-94235 Cachan Cedex, France ** now at Laboratoire de Mécanique des Structures Navales, ENSIETA 2 rue François Verny, F-29806 Brest Cedex 9, France
${ }^{* * *}$ Laboratoire d'optique physique, ESPCI/CNRS-UPR A0005 10 rue Vauquelin, F-75231 Paris Cedex 05, France
${ }^{* * * *}$ ARCELOR Research voie romaine BP 30320, F-57283 Maizières-lès-Metz Cedex, France

${ }^{1}$ Corresponding author: Fax: +33 2983487 30, E-mail: cedric.doudard@ensieta.fr 


\section{ABSTRACT}

A probabilistic two-scale model was recently developed to describe high-cycle fatigue (HCF) properties of steels associated with an identification method of the scatter based on thermal measurements. Up to now, this theoretical framework was used for uniaxial load histories. It is proposed to modify the probabilistic two-scale model to account for the effect of a multiaxial and proportional load histories on HCF properties. This modification consists in the introduction of an equivalent activation stress in the process controlling the plasticity kinetics. Thermal measurements are performed under biaxial tensioncompression load histories to identify and validate an HCF criterion.

Keywords: Microplasticity, Poisson point process, Weibull model, Multiaxial fatigue, thermal measurements. 


\section{Introduction}

Components of engineering structures such as car chassis or steering knuckles are subjected to multiaxial load histories. The multiaxial fatigue behavior of materials and structures, which depends on the loading-path, is still difficult to describe. Because fatigue data are usually scattered, classic identification techniques of fatigue properties (e.g., by using the staircase test [1]) are difficult and require the use of use many specimens. This is even more difficult if one wants to study HCF fatigue of materials under multiaxial loadings. Because the methods based on the staircase tests are time consuming and expensive, other procedures are sought to have a good understanding of the effect of multiaxial load histories on fatigue response. In the present paper, thermal measurements are used to evaluate endurance properties under multiaxial states of stresses.

Several authors have worked on a rapid estimation of the mean fatigue limit [28]. It is based upon temperature measurements of the studied specimen under mechanical cyclic loadings. The results of so-called "heating tests" (i.e., thermal effects associated with cyclic loading) by plotting the change of the mean steady-state temperature with the stress amplitude applied to the specimen. A correlation is obtained between the fatigue limit of some materials and the stress level beyond which an increase in the specimen temperature can be observed by using thermocouples [7, 8] or infrared (IR) cameras [2-6]. If the dissipated energy is induced by microplasticity, which does not have an influence on the macroscopic (and elastic) behavior of the specimen, and if high-cycle fatigue (HCF) failure is caused by microplasticity, correlation between the two tests (i.e., "heating test" and classical fatigue tests) can be obtained [9].

A probabilistic model based on afore-mentioned hypotheses was recently developed and an identification method of the scatter proposed by using the analysis of 
thermal effects [8]. However, the latter were only studied for stresses uniaxial states. The main goal of the present work is to propose a new mechanical test associated with the measurement of temperature to identify a multiaxial HCF criterion. The method consists in measuring temperatures for different proportional loading-paths in the stress plane (the test are performed on a cruciform specimen under biaxial tension-compression load histories). Special care is paid to the definition of the specimen geometry so that the temperature and the stress fields in the central part of the specimen are uniform.

The paper is divided into four main sections. In the first one, the probabilistic two-scale model for HCF and the analysis of thermal effects under mechanical cyclic loading are presented (a more detailed presentation can be found in Ref. [9]). This HCF model is based on a multi-scale approach where microplasticity occurs on sites described as a Poisson point process. Within the weakest link theory [10], this proposed model corresponds to a Weibull law for the fatigue limits. In the new version of the model presented herein, an equivalent activation stress (i.e., an equivalent fatigue stress) is introduced in the Poisson point process to account for the influence of the multiaxial state of stress on the endurance limits.

The second section deals with the development of a "heating test" under multiaxial cyclic loadings. The strategy for uniaxial, mechanical and cyclic loadings is generalized to the case of biaxial tension-compression loadings. The first experimental results are presented. The latter are used in the third section to identify an equivalent activation stress for HCF fatigue under multiaxial loadings. In the last section, the identification procedure is applied to a dual-phase steel. To be used in industry, the knowledge of the multiaxial fatigue properties are needed [9, 11-19]. Different choices of equivalent activation stresses are presented and it is shown that one of them yields better results. 


\section{Probabilistic two-scale model to describe thermal effects and HCF life}

In the present paper, only loading cases with no mean stress are studied. Let $\Sigma_{0}$ and $f_{r}$ be the amplitude and frequency of the stress history. It is assumed that HCF damage is localized at the microscopic scale and is induced by microplastic activity. To describe this activity, a set of elasto-plastic inclusions, called sites, randomly distributed within an elastic matrix is considered. These sites of volume $\mathrm{V}_{0}$ become active when plasticity occurs (i.e., when the von Mises equivalent stress level is greater than the microscopic yield stress of the considered site $\sigma_{y}$ ). In metals, the onset of microplasticity is random (i.e., the sites become active for different equivalent stress levels). It is therefore assumed that the probability of finding $k$ active sites within a domain $\Omega$ of volume $\mathrm{V}_{\Omega}$ follows a Poisson distribution [20, 21]

$$
\mathrm{P}_{\mathrm{k}}(\Omega)=\frac{[-\mathrm{N}(\Omega)]^{k}}{k !} \exp [-\mathrm{N}(\Omega)]
$$

where $\mathrm{N}(\Omega)$ is equal to the average number of active sites. The intensity of the Poisson point process $\lambda$ (i.e., the average density of active sites) reads

$$
\mathrm{N}(\Omega)=\lambda \mathrm{V}_{\Omega}
$$

The intensity of the process depends on an equivalent activation stress $\Sigma_{\mathrm{a}}$

$$
\lambda\left(\Sigma_{\mathrm{a}}\right)=\frac{1}{\mathrm{~V}_{0}}\left(\frac{\Sigma_{\mathrm{a}}}{\mathrm{S}_{0}}\right)^{\mathrm{m}},
$$

where $\mathrm{V}_{0} \mathrm{~S}_{0}^{\mathrm{m}}$ and $m$ are two parameters depending on the considered material.

The stress tensor $\underline{\underline{\sigma}}$ in an inclusion is related to the macroscopic stress tensor $\underline{\underline{\Sigma}}$ and the corresponding plastic strain tensor $\underset{\underline{\varepsilon}}{\mathrm{p}}$ by

$$
\underline{\underline{\sigma}}=\underline{\underline{\Sigma}}-2 \mu(1-\beta) \underline{\underline{\varepsilon}}^{\mathrm{p}}
$$


with $\beta=\frac{2(4-5 v)}{15(1-v)}$ given by the Eshelby analysis of a spherical inclusion, $\mu$ and $v$ the shear modulus and Poisson's ratio of the dual-phase steel, respectively [22-24]. A linear kinematic hardening is assumed for the elasto-plastic behavior. Consequently, the back

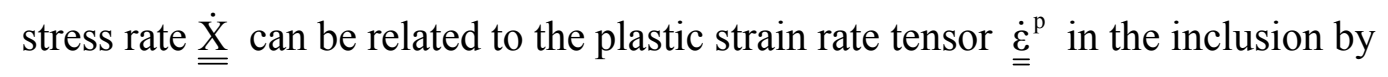

$$
\underline{\underline{X}}=\frac{2}{3} \mathrm{C} \underline{\underline{\dot{\varepsilon}}}^{\mathrm{p}}
$$

where $C$ is a material-dependent parameter, and a dotted variable corresponds to its first derivative with respect to time [25]. The direction of the plastic strain rate tensor is given by a classic normality rule

$$
\stackrel{\dot{\varepsilon}}{=}^{\mathrm{p}}=\dot{\lambda} \frac{\partial \mathrm{f}}{\partial \underline{\underline{S}}}
$$

with the usual Kuhn-Tucker conditions, $\underset{\underline{S}}{=} \underset{\underline{\sigma}}{\underline{\sigma}}-\frac{1}{3} \operatorname{trace}(\underline{\underline{\sigma}})_{\underline{\underline{I}}}$ is the deviatoric stress tensor, $\underline{I}$ the unit second order tensor, $\dot{\lambda}$ the plastic multiplier and $f$ the yield surface given by

$$
\mathrm{f}=\mathrm{J}_{2}(\underline{\underline{\mathrm{S}}}-\underline{\underline{X}})-\sigma_{\mathrm{y}} \leq 0
$$

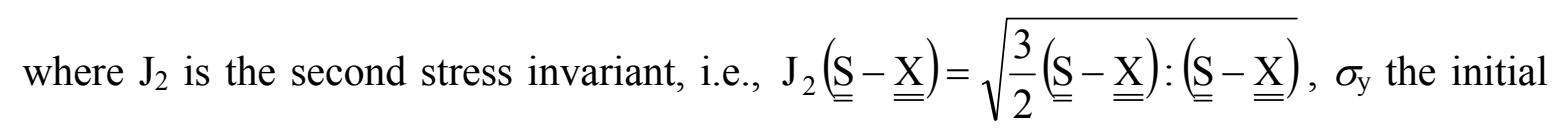
yield stress of a site and ':' the tensorial product contracted with respect to two indices. The intrinsic dissipated energy $\mathrm{D}_{\text {site }}$ in one site over a loading cycle for a given yield stress $\sigma_{\mathrm{y}}$ and a von Mises equivalent stress amplitude $\Sigma_{0}^{\mathrm{eq}}$ can be expressed as

$$
\mathrm{D}_{\text {site }}\left(\Sigma_{0}^{\mathrm{eq}}, \sigma_{\mathrm{y}}\right)=\int_{\text {cycle }} \mathrm{V}_{0}(\underline{\underline{\sigma}}-\underline{\underline{\mathrm{X}}}): \underline{\underline{\dot{\varepsilon}}}^{\mathrm{p}} d t=\frac{4 \mathrm{~V}_{0} \sigma_{\mathrm{y}}}{\mathrm{h}}\left\langle\Sigma_{0}^{\mathrm{eq}}-\sigma_{\mathrm{y}}\right\rangle
$$

where $h=C+3 \mu(1-\beta)$ is the hardening modulus and $\langle$.$\rangle are the Macauley brackets (i.e.,$ positive part of '.'). 
With a Poisson point process, $\frac{\mathrm{d} \lambda}{\mathrm{d} \Sigma} \mathrm{V}_{\Omega} \mathrm{d} \Sigma$ corresponds to the mean number of inclusions activated for an equivalent stress amplitude ranging from $\Sigma$ and $(\Sigma+\mathrm{d} \Sigma)$ in a domain of volume $V_{\Omega}$, i.e., the number of sites whose mean fatigue limit lies between $\Sigma$ and $(\Sigma+\mathrm{d} \Sigma)$, and whose dissipated energy during a load cycle is $\mathrm{D}_{\text {site }}\left(\Sigma_{0}^{\mathrm{eq}}, \Sigma\right)$. The global dissipated energy density $\Delta$ per cycle is given by

$$
\Delta=\int_{0}^{\Sigma_{0}^{\mathrm{eq}}} \mathrm{D}\left(\Sigma_{0}^{\mathrm{eq}}, \Sigma\right) \frac{\mathrm{d} \lambda\left(\Sigma_{\mathrm{a}}\right)}{\mathrm{d} \Sigma} \mathrm{d} \Sigma .
$$

The temperature is determined by integrating the heat conduction equation in which the mean microplastic dissipation (i.e., the cyclic dissipation multiplied by the load frequency $f_{r}$ ) is included

$$
\dot{\theta}+\frac{\theta}{\tau_{\mathrm{eq}}}=\frac{\Delta \mathrm{f}_{\mathrm{r}}}{\rho \mathrm{c}},
$$

where $\tau_{\text {eq }}$ is a time constant that depends on the heat transfer boundary condition, $\rho$ the mass density, $\mathrm{c}$ the specific heat capacity and $\theta$ the temperature [9]. The corresponding steady-state temperature $\bar{\theta}$ reads

$$
\bar{\theta}=\frac{4 \mathrm{f}_{\mathrm{r}} \tau_{\mathrm{eq}}}{\mathrm{h} \rho \mathrm{c}} \int_{0}^{\Sigma_{0}^{\mathrm{eq}}} \Sigma\left(\Sigma_{0}^{\mathrm{eq}}-\Sigma\right) \frac{\mathrm{d}}{\mathrm{d} \Sigma}\left(\frac{\Sigma_{\mathrm{a}}}{\mathrm{S}_{0}}\right)^{\mathrm{m}} \mathrm{d} \Sigma .
$$

To integrate Eq. (11), the equivalent activation stress must be related to the von Mises equivalent stress. If $\Sigma_{\mathrm{a}}=\Sigma_{0}^{\mathrm{eq}}, \bar{\theta}$ is given by

$$
\bar{\theta}=\eta \mathrm{V}_{0} \frac{\mathrm{m}}{(\mathrm{m}+1)(\mathrm{m}+2)} \frac{\left(\Sigma_{0}^{\mathrm{eq}}\right)^{\mathrm{m}+2}}{\left(\mathrm{~V}_{0}^{1 / \mathrm{m}} \mathrm{S}_{0}\right)^{\mathrm{m}}},
$$

with $\eta=4 \mathrm{f}_{\mathrm{r}} \tau_{\mathrm{eq}} / \mathrm{h} \rho \mathrm{c}$. Equation (12) shows a gradual change of the steady-state temperature with the equivalent stress amplitude in agreement with experimental results [8, 
9]. Another choice can be made for the equivalent activation stress. The latter can be related to the first and second invariants of the stress amplitude

$$
\Sigma_{\mathrm{a}}=\Sigma_{0}^{\mathrm{eq}}\left(1-\alpha\left(\mathrm{P}_{0}-\frac{1}{3}\right)\right)
$$

where $\alpha$ is a material-dependent parameter. This expression accounts for the well-known influence of hydrostatic stress $\mathrm{P}_{0}=\frac{1}{3} \operatorname{tr}\left(\underline{\underline{\Sigma_{0}}}\right)$ on fatigue properties. With this second equivalent activation stress [Eq. (13)], the steady-state temperature then reads

$$
\bar{\theta}=\eta \mathrm{V}_{0} \frac{\mathrm{m}}{(\mathrm{m}+1)(\mathrm{m}+2)} \frac{\left(\Sigma_{0}^{\mathrm{eq}}\right)^{\mathrm{m}+2}}{\left(\mathrm{~V}_{0}^{1 / \mathrm{m}} \mathrm{S}_{0}\right)^{\mathrm{m}}}\left(1-\alpha\left(\mathrm{P}_{0}-\frac{1}{3}\right)\right)^{\mathrm{m}}
$$

The experimental results under biaxial tension-compression loadings, presented hereafter, enable us to discriminate between the two propositions for the equivalent activation stress. This is the main goal of the last section of the paper.

For a uniaxial test with a stress amplitude $\Sigma_{0}$, the steady-state temperature reads

$$
\bar{\theta}=\eta \mathrm{V}_{0} \frac{\mathrm{m}}{(\mathrm{m}+1)(\mathrm{m}+2)} \frac{\left(\Sigma_{0}\right)^{\mathrm{m}+2}}{\left(\mathrm{~V}_{0}^{1 / \mathrm{m}} \mathrm{S}_{0}\right)^{\mathrm{m}}} .
$$

Equation (15) shows that the temperature history can be used to identify the material parameter $m$ characterizing the random microstructure of the studied material [26].

By using the same framework, the proposed model can be used to describe HCF results. Within the weakest link theory that is usually considered in HCF [10], the failure probability $\mathrm{P}_{\mathrm{F}}$ of a domain $\Omega$, of volume $\mathrm{V}$, under uniform stress is equal to the probability of finding at least one active site

$$
\mathrm{P}_{\mathrm{F}}=\mathrm{P}_{\mathrm{k} \geq 1}(\mathrm{~V})=1-\exp (-\lambda \mathrm{V})
$$


In the present case, it is assumed that initiation occurs within the volume of the materials. By using the intensity $\lambda$ expressed as a power law of the equivalent stress of activation (see Eq. (3)), the proposed model corresponds to a Weibull model [27, 28]

$$
\mathrm{P}_{\mathrm{F}}=1-\exp \left[-\frac{\mathrm{V}}{\mathrm{V}_{0}}\left(\frac{\Sigma_{\mathrm{a}}}{\mathrm{S}_{0}}\right)^{m}\right] .
$$

Equation (17) shows that $\Sigma_{\mathrm{a}}$ corresponds to the equivalent fatigue stress. The HCF life prediction is often characterized by the mean fatigue limit $\bar{\Sigma}_{\infty}$ and the coefficient of variation $\mathrm{CV}$ (i.e., the standard deviation divided by the mean fatigue limit) given by, respectively

$$
\begin{gathered}
\bar{\Sigma}_{\infty}=\mathrm{S}_{0}\left(\frac{\mathrm{V}_{0}}{\mathrm{~V}}\right)^{\frac{1}{\mathrm{~m}}} \Gamma\left(1+\frac{1}{\mathrm{~m}}\right), \\
\mathrm{CV}=\frac{\sqrt{\Gamma\left[1+\frac{2}{\mathrm{~m}}\right]-\Gamma^{2}\left[1+\frac{1}{\mathrm{~m}}\right]}}{\Gamma\left(1+\frac{1}{\mathrm{~m}}\right)} .
\end{gathered}
$$

Equation (19) shows that the scatter in fatigue only depends on $m$, the Weibull modulus, whereas the mean fatigue limit and the corresponding standard deviation is a volumedependent.

To model the Wöhler ( $\mathrm{S}-\mathrm{N})$ curve associated with a failure probability $\mathrm{P}_{\mathrm{F}}$ for a tensile fatigue test, it is assumed that crack initiation is associated to a critical value of the cumulative dissipated energy $E_{c}$ for a site whose yield stress is equal to the fatigue limit

$$
\mathrm{ND}_{\text {site }}\left(\Sigma_{0}, \Sigma_{\infty}\left(\mathrm{P}_{\mathrm{F}}\right)\right)=\mathrm{E}_{\mathrm{c}}
$$

where $N$ is the number of cycles to failure (i.e., the propagation stage is neglected with respect to the initiation stage). The number of cycles leading up to crack initiation can then be deduced 


$$
\mathrm{N}=\frac{\mathrm{A}}{\left\langle\Sigma_{0}-\Sigma_{\infty}\left(\mathrm{P}_{\mathrm{F}}\right)\right\rangle \Sigma_{\infty}\left(\mathrm{P}_{\mathrm{F}}\right)},
$$

where $\mathrm{A}=\frac{\mathrm{h} \mathrm{E}_{\mathrm{c}}}{4 \mathrm{~V}_{0}}$ is a material-dependent parameter. From multiaxial fatigue tests, the previous expression is extended

$$
\mathrm{N}=\frac{\mathrm{A}}{\left\langle\Sigma_{\mathrm{a}}-\Sigma_{\infty}\left(\mathrm{P}_{\mathrm{F}}\right)\right\rangle \Sigma_{\infty}\left(\mathrm{P}_{\mathrm{F}}\right)}
$$

The proposed model depends only on the choice of the equivalent activation stress $\Sigma_{\mathrm{a}}$ and four material parameters, namely, $\mathrm{S}_{0}\left(\mathrm{~V}_{0}\right)^{1 / m}, \eta V_{0}, m$ and $A$. The identification of the parameters is possible by using temperature measurements in a uniaxial experiment and tensile fatigue tests $[8,9]$. A multiaxial test is therefore needed to choose the equivalent activation stress $\Sigma_{\mathrm{a}}$. The following section deals with the design of this multiaxial test under biaxial tension-compression cyclic loadings.

\section{Development of a biaxial test}

The material studied herein is a ferrite-martensite steel (approximately $15 \mathrm{wt} \%$ of martensite, Arcelor designation: DP60) in its cold-rolled state. The chemical composition of the dual-phase steel is given in Table 1. The mechanical properties obtained from monotonic tensile tests on samples in the rolling direction are given in Table 2. This steel has a good capacity of strain hardening. Consequently, the dual-phase steels are used in the automotive industry where metal forming processes need these types of properties.

The basic idea of the multiaxial test is to load a cross-shaped specimen in tensioncompression along two perpendicular directions. An ad hoc cruciform specimen has been designed for this study. The latter is made of a stacking of three metal sheets (Fig. 1). A particular attention is paid to the uniformity of the temperature field in the gauge section 
(i.e., central part of the cruciform specimen). Consequently, the stress field must also be uniform (so will be the dissipation due to microplasticity), and the heat transfer boundary conditions adequate (i.e., the spatial variation of the temperature due to heat conduction must be minimized). The size of the gauge region is close to the size of the gauge section of the uniaxial specimen. Its shape is circular ended by a fillet. Three plates (Fig. 1) are machined separately and then glued together with epoxy resin to create the gauge region. The orientations of the different plates are $0^{\circ}$ or $90^{\circ}$ with respect to the rolling direction because of the quasi isotropy of the sheet steel. Slots are machined to minimize "crosslink" between the two axes of loading. The values of the minimum thickness of the fillet, $e$ (Fig. 2), of the minimum distance, $\phi$, and of the location of the slots in the connecting arms $\mathrm{L}_{\mathrm{pt}}$ are optimized by using FE simulations to obtain a von Mises equivalent stress field as uniform as possible. With the selected triplet of geometric parameters $\left(e, \phi, \mathrm{L}_{\mathrm{pt}}\right)$, the standard deviation of the von Mises equivalent stress distribution within the gauge region under uniaxial tensile load is about $0.7 \%$ of the mean von Mises equivalent stress. Conversely, under an equibiaxial load, the standard deviation of the von Mises equivalent stress distribution within the gauge region is about $0.35 \%$ of the mean von Mises equivalent stress.

The tests are carried out on a multiaxial testing machine (ASTRÉE, Fig. 3). This testing machine has six servohydraulic actuators. The loading frame is made of a fixed base, four vertical columns, and a mobile crosshead. The testing space $\left(650 \times 650 \times 1500 \mathrm{~mm}^{3}\right)$ is delimited by the six actuators; four of them are used for the present test. The two vertical actuators, bolted to the mobile crosshead and on the fixed base respectively, have a $250 \mathrm{kN}$ load capacity and a $250 \mathrm{~mm}$ stroke range. The four horizontal actuators have a $100 \mathrm{kN}$ load capacity and a $250 \mathrm{~mm}$ stroke range. The horizontal actuators are fixed on the vertical columns and they can be relocated in any 
vertical position. For protection purposes of the actuators at specimen failure (which can cause extremely high side and twist forces), additional hydraulic bearings are installed in front of each actuator. Two hydraulic power stations can generate a $660 \mathrm{l} / \mathrm{min}$ maximum flow rate. Closed-loop control for each actuator is provided by a digital controller (Schenck 59 serial Hydropuls). The controller monitors and provides signal conditioning for each loading actuator position channel. Each axis (X, Y and Z) has its own dedicated strain channel for signal conditioning and control. Input signals can come from a variety of strain measuring devices (e.g., strain gauges, extensometer or even digital image correlation). Command waveform generation for each channel can be provided either by the controller internal generators or externally via a personal computer. Computer test control and data acquisition are performed by an object-oriented programming software (LabVIEW $\left.{ }^{\mathrm{TM}}[29]\right)$. The digital controller combined with this software package provides a highly versatile capability where numerous custom-made tests can be developed. The digital controller allows each actuator to be controlled independently or in centroid control. The centroid control mode uses a relationship between two actuators along the same load axis to maintain the center of the specimen motionless. The digital controller enforces centroid control by using special algorithms to operate the valve driver of each actuator. Figure 4 illustrates how the centroid control algorithms work for a load controlled test. For each axis pair (e.g., $\mathrm{Y}^{+}$and $\mathrm{Y}^{-}$), the controller uses the sum of the forces and the difference of displacements along the considered axis. This centroid control has been used in all the biaxial tests presented hereafter. The main difficulty of this test is to prevent the specimen from bending. To meet this requirement, the specimen is placed horizontally and an accurate vertical positioning of each actuator must be achieved.

The main goal of the first series of tests is to check the uniformity of the temperature field. First, an equibiaxial and cyclic tension-compression test was performed. 
This load-controlled test had a $40 \mathrm{kN}$ amplitude and a $5 \mathrm{~Hz}$ frequency. The temperature field is monitored using an infrared camera (JADE IRFPA, resolution: $320 \times 256$ pixels, medium wave with a $3-5 \mu \mathrm{m}$ spectral range) at the frequency of one frame per second. The sample has been painted in matt black, on the one hand, to increase the emissivity of the sample, and on the other hand, to decrease the influence of the environment. Movies are shot until steady state is reached. Figure 5 shows the temperature of 9 different points in a $44 \times 33 \mathrm{~mm}^{2}$ rectangle of the tested region. Post-processing of the IR movies shows the uniformity of the temperature field in the gauge region despite stress concentrators around fillets and slots. The temperature change due to heat conduction can be neglected since it is the same at each examined point up to an additive constant. Consequently, since the temperature field is uniform, in the sequel the temperature is monitored by using a single copper/copper-nickel thermocouple installed on the center of the gauge region.

To monitor the load history, two perpendicular strain gauges (Micro Measurement EP-08-062TT-120) are installed on each side of the specimen. When the actuators are not correctly positioned, an important bending strain is observed during clamping. Moreover, asymmetric strains appear during loading and a different behavior is observed between tensile and compressive load histories. When an accurate positioning of the actuators is obtained, the strains due to clamping are of the order of $5 \times 10^{-5}$, i.e., corresponding to a $10 \mathrm{MPa}$ stress level and a symmetric behavior follows (e.g., for an equibiaxial load history as shown in Fig. 6a). The stress can be regarded as uniform in thickness. The phase shift between the axes was studied for an equibiaxial load. Figure $6 \mathrm{~b}$ shows that the load history is validated (i.e., the load path is nearly proportional). 


\section{Experimental identification of an "activation surface” under biaxial loadings}

The main goal of this section is to present a series of tests to identify an "equivalent activation stress" under biaxial tension-compression loadings in HCF by using temperature measurements. One single cruciform sample is used to identify the equivalent activation stress.

Different proportional loading paths (Fig. 7a) are successively applied to the sample. For each path, the load is of the same type. It consists in applying successive series of 3,000 cycles for different increasing stress amplitudes $\Sigma_{0}$ (Fig. 7b). For each stress amplitude, the temperature of the sample $\theta$ is recorded (Fig. 7c). The mean temperature becomes stable after about 1,000 cycles and equals $\bar{\theta}\left(\Sigma_{0}\right)$. Figure $7 \mathrm{~d}$ shows the change of the mean steady-state temperature $\bar{\theta}\left(\Sigma_{0}\right)$ with the stress amplitude for a dual-phase steel. When the stabilized temperature reaches a given offset, the loading path changes to the next one. For each load path, the stress amplitude is depicted by a line in the stress plane (Fig. 7e), i.e., the line represents the stress amplitude. It is therefore possible to evaluate an "activation surface" showing the different stress amplitudes leading to the same temperature offset associated with each load history. Figure 8 shows the result obtained for a dual-phase steel with a $1^{\circ} \mathrm{C}$ offset. The curve is convex, nearly symmetric with respect to the first bisector. This is related to the quasi isotropy of the material.

The equibiaxial load history appears twice during the series of proportional loads presented before so that the load history effect can be studied. The equibiaxial load is performed a first time on the specimen and a second time after nearly 96,000 cycles (i.e., 12,000 cycles multiplied by 8 paths). The two responses are reported in Fig. 9a and are almost identical. The stress levels corresponding to a $1{ }^{\circ} \mathrm{C}$ offset show a difference of 4 MPa, i.e., $2.5 \%$ of their value. The load history effect can therefore be neglected. To 
analyze the influence of the offset value on the shape of the "activation surface", four series of tests were performed using different offset values, namely, $0.4^{\circ} \mathrm{C}, 0.6^{\circ} \mathrm{C}, 0.8^{\circ} \mathrm{C}$ and $1{ }^{\circ} \mathrm{C}$. Figure $9 \mathrm{~b}$ shows the shape of the "activation surfaces". The greater the offset, the larger the "activation surface". Yet the shape of the "activation surface" is not affected by the offset value (Fig. 9b).

\section{Identification procedure}

This section shows how to identify the different parameters, namely, $\mathrm{S}_{0}\left(\mathrm{~V}_{0}\right)^{1 / \mathrm{m}}$ characterizes the level of the mean fatigue limit [Eq. (18)], $\eta \mathrm{V}_{0}$ is a material dependent parameter to describe the temperature changes [Eq. (12)], $m$ measures the scatter of the fatigue limits [Eq. (19)], and $A$ characterizes the initiation criterion [Eq. (21)]. First, the two parameters $A$ and $\bar{\Sigma}_{\infty}$ (i.e., parameter $\mathrm{S}_{0}\left(\mathrm{~V}_{0}\right)^{1 / m}$ for a given volume [Eq. (18)] of Stromeyer's law [30]) are determined from the analysis of the classical Wöhler curve obtained in cyclic tension/compression

$$
\mathrm{N}=\frac{\mathrm{A}}{\left\langle\Sigma_{0}-\bar{\Sigma}_{\infty}\right\rangle \bar{\Sigma}_{\infty}}
$$

where 15 samples are usually needed (Fig. 10a). Then the values for $m$ and $\eta V_{0}$ are identified by using the temperature measurements [Eq. (15)] for which an additional specimen is used in a cyclic tension/compression test. The results of the identification are shown in Fig. 10b. The proposed model gives a good description of the temperature measurements, especially it accounts for the gradual change in temperature with the applied stress. The classic approach used for the analysis of this test [2-6] cannot describe this transition regime [9]. Consequently, 16 (i.e., 15+1) samples are needed to identify the four parameters. 
To identify the equivalent activation stress, the "activation surface", which is obtained with one additional sample, is used. Figure 11a shows the comparison between the experimental results and the prediction of the present model with $\Sigma_{\mathrm{a}}=\Sigma_{0}^{\mathrm{eq}}$ [i.e., when utilizing Eq. (12)]. The model is fitted by using the results of path no. 3 (Fig. 7a). The difference between experiments and predictions is about $13 \%$ in the case of shear. If the second choice for the equivalent activation stress is considered [Eq. (13)], the prediction is better (Fig. 11b). The difference between experimental results and predictions is about 3\% when $\alpha=0.39$. This result shows that the equivalent activation stress has to be related both to the first and second invariants of the stress amplitude for the steel studied herein. This procedure allows for the determination of an equivalent stress activation, which is validated for each path in the stress plane. Consequently, 17 (i.e., 15+1+1) samples are needed to identify the four parameters of the model and the equivalent activation stress.

Two fatigue results are generally used to identify classic fatigue criteria (namely, a torsion test, which corresponds to path no. 1 for this study and a bending test, which corresponds to path no. 3). The proposed identification method makes identification faster (17 samples instead of 60-100 samples), but also validation of identification for any direction in the stress plane.

\section{Summary}

A probabilistic two-scale model accounting for the effect of multiaxial proportional loadings on high-cycle fatigue properties was proposed. It is based upon a Poisson point process that allows one to relate the temperature changes under multiaxial loadings to HCF properties in a unified way.

A new configuration under biaxial tension-compression cyclic loadings is presented. A first (positive) check on the uniformity of the temperature and stress fields 
was performed. By using different proportional loading paths, an activation surface was identified from temperature measurements. By using the probabilistic model described herein, an equivalent activation stress based on a first/second invariant $\left(\mathrm{I}_{1}-\mathrm{J}_{2}\right)$ criterion of the stress amplitude leads to the best agreement with experimental data.

The next step of the study deals with the introduction in the model of the effects of the non-proportionality of the load history on HCF properties. This work is still in progress.

\section{Acknowledgements}

The authors wish to thank ARCELOR and Nippon Steel Corporation for funding this work. 


\section{References}

[1] Bathias C. and Baïlon J.-P. La fatigue des matériaux et des structures. Hermès, Paris (France), 1997.

[2] Luong M. P. Infrared thermography of fatigue in metals. SPIE 1992; 1682, 222-233.

[3] Bérard J.-Y., Rathery S. and Béranger A.-S. Détermination de la limite d'endurance des matériaux par thermographie infrarouge. Mat. Techn. 1998; 1-2, 55-57.

[4] Krapez J.-C., Pacou D. and Bertin C. Application of lock-in thermography to a rapid evaluation of the fatigue limit in metals. 5th AITA, Int. Workshop on Advanced Infrared Techn. and Appl., Venezia (Italy), Ed. E. Grinzato et al., 1999, pp. 379-385.

[5] La Rosa G. and Risitano A. Thermographic methodology for rapid determination of the fatigue limit of materials and mechanical components. Int. J. Fat. 2000; 22 [1], $65-73$.

[6] Mabru C. and Chrysochoos A. Dissipation et couplages accompagnant la fatigue de matériaux métalliques. Photomécanique 2001, Ed. Y. Berthaud, M. Cottron, J.-C. Dupré, F. Morestin, J.-J. Orteu and V. Valle, GAMAC, 2001, pp. 375-382.

[7] Galtier A., Bouaziz O. and Lambert A. Influence de la microstructure des aciers sur leurs propriétés mécaniques. Méc. Ind. 2002; 3 [5], 457-462.

[8] Doudard C., Calloch S., Hild F., Cugy P. and Galtier A. Identification of the scatter in high cycle fatigue from temperature measurements. C.R. Mecanique 2004; 332 [10], 795-801.

[9] Doudard C., Calloch S., Cugy P., Galtier A. and Hild F. A probabilistic two-scale model for high cycle fatigue life predictions. Fat. Fract. Eng. Mat. Struct. 2005; 28 [3], 279-288. 
[10] Freudenthal A. M. Statistical Approach to Brittle Fracture. Fracture, vol. 2, Academic Press, Ed. H. Liebowitz, 1968, pp. 591-619.

[11] Speich G. R. and Miller R. L. Structure and properties of dual phase steels. Ed. R. A. Kot and J. W. Morris, AIME, New York (USA) 1979, pp. 146-181.

[12] Li Z., Han J., Wang Y. and Kuang Z. Low-cycle fatigue investigations and numerical simulations on dual phase steel with different microstructures. Fat. Fract. Eng. Mat. Struct. 1990; 3 [3], 229-240.

[13] Gustavsson A. and Melanger A. Variable-amplitude fatigue of a dual-phase sheet steel subjected to prestrain. Int. J. Fat. 1994; 16, 503-509.

[14] Lei T. C., Lin G. Y. and Cui Y. X. Dislocation substructures in ferrite of plain carbon dual-phase steels after fatigue fracture. Fat. Fract. Eng. Mat. Struct. 1994; 17 [4], 451-458.

[15] Hashimoto T. M. and Pereira M. S. Fatigue life studies in carbon dual-phase steels. Int. J. Fat. 1996; 18 [8], 529-533.

[16] Nakajima K., Kamiishi S., Yokoe M. and Miyata T. The influence of microstructural morphology and prestrain on fatigue crack propagation of dual-phase steels in the near-threshold region. ISIJ International 1999; 39 [5], 486-492.

[17] Sarwar M. and Priestner R. Fatigue crack propagation behaviour in dual phase steel. J. Mat. Eng. Perform. 1999; 8, 245-251.

[18] Wang Z. G. and Ai S. H. Fatigue of martensite-ferrite high strength low alloy dual steels. ISIJ international 1999; 39 [8], 747-759.

[19] Haque M. E. and Sudhakar M. S. ANN based prediction model for fatigue crack growth in DP steel, ". Fat. Fract. Eng. Mat. Struct. 2001; 23, 63-68. 
[20] Gulino R. and Phoenix S. L. Weibull Strength Statistics for Graphite Fibres Measured from the Break Progression in a Model Graphite/Glass/Epoxy Microcomposite. J. Mater. Sci. 1991; 26 [11], 3107-3118.

[21] Jeulin D. Modèles morphologiques de structures aléatoires et changement d'échelle. thèse d'État, Université de Caen 1991.

[22] Eshelby J. D. The Determination of the Elastic Field of an Ellipsoidal Inclusion and Related Problems. Proc. Roy. Soc. London 1957; A 241, 376-396.

[23] Berveiller M. and Zaoui A. An extension of the self-consistent scheme to plastically flowing polycrystals. J. Mech. Phys. Solids 1979; 26, 325-344.

[24] Kröner E. On the plastic deformation of polycristals. Acta Met. 1984; 9, 155-161.

[25] Lemaitre J. and Chaboche J.-L. Mécanique des matériaux solides. Dunod, Paris (France) 1985.

[26] Cugy P. and Galtier A. Microplasticity ant temperature increase in low carbon steel. Stockholm (Sweden), Ed. t. I. F. Conference 2002.

[27] Weibull W. A Statistical Theory of the Strength of Materials. Roy. Swed. Inst. Eng. Res., 1939; Report 151.

[28] Weibull W. A Statistical Distribution Function of Wide Applicability. ASME J. Appl. Mech. 1951; 18 [3], 293-297.

[29] Cottet F. LabVIEW Programmations et applications. Dunod, Paris (France), 2001.

[30] Stromeyer C. E. The determination of fatigue limits under alternating stress conditions. Proc. Roy. Soc. London 1914; A90, 411-425. 


\section{List of figures}

Figure 1: Three plates used to make the sample.

Figure 2: $\quad$ Definition of three parameters $e, \phi$ and Lpt optimized by using a FE analysis.

Figure 3: The multiaxial testing machine ASTRÉE.

Figure 4: Schematic of the centroid control system for one axis.

Figure 5: Measurement of the temperature field: (-a-) position of the camera in the testing machine; (-c-) temperature changes for various points (-b-).

Figure 6: Change in strains on the bottom face vs. those on the top face measured by strain gauges.

Figure 7: Description of the experimental strategy: (-a-) various testing directions in the stress plane; (-b-) successive series of 3,000 cycles of increasing stress amplitudes $\Sigma_{0} ;(-\mathrm{c}-)$ change in temperature during 3,000 cycles; (-d-) change in mean steady-state temperature with the load amplitude and definition of an offset for the first direction; (-e-) experimental result for this direction in the stress plane.

Figure 8: $\quad$ Activation temperature obtained for a dual-phase steel with a $1{ }^{\circ} \mathrm{C}$ offset. 
Figure 9: Validation of the testing strategy: (-a-) comparison between the change in temperature with the stress amplitude for the first equibiaxial test (a) and (b) and the same one carried out after the other loading directions; (-b-) activation surfaces for different offset values.

Figure 10: Identification of $A$ and $\bar{\Sigma}_{\infty}(-a-)$ from a classical Wöhler curve, $\eta V_{0}$ and $m$ from temperature measurements (-b-) for the studied dual-phase steel $\left(f_{r}=10 \mathrm{~Hz}, \Sigma_{m}=0\right)$ in a tension/compression test.

Figure 11: Comparisons between experimental activation surfaces and predictions for a von Mises equivalent activation stress (-a-) and for an equivalent activation stress related to the first and second invariants of the stress amplitude. 


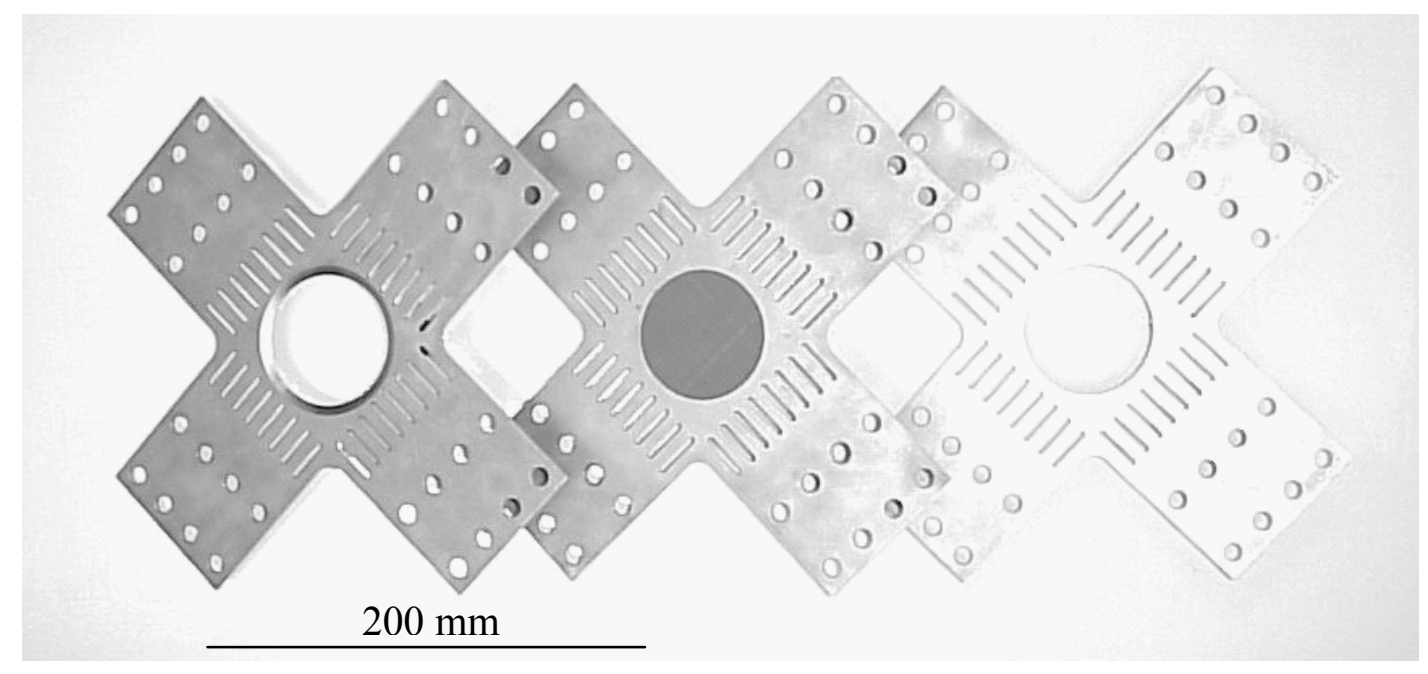

Figure 1. Doudard et al. 

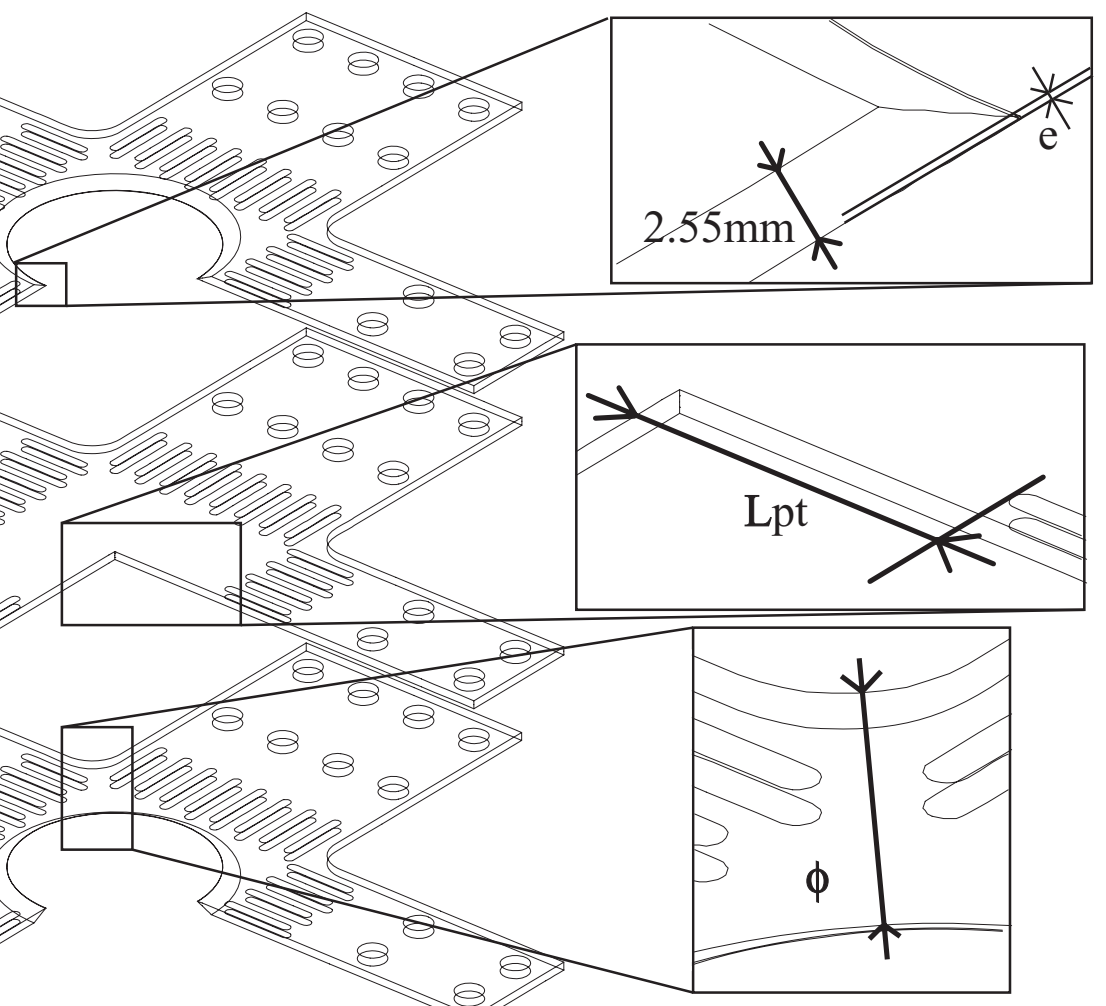

Figure 2. Doudard et al. 


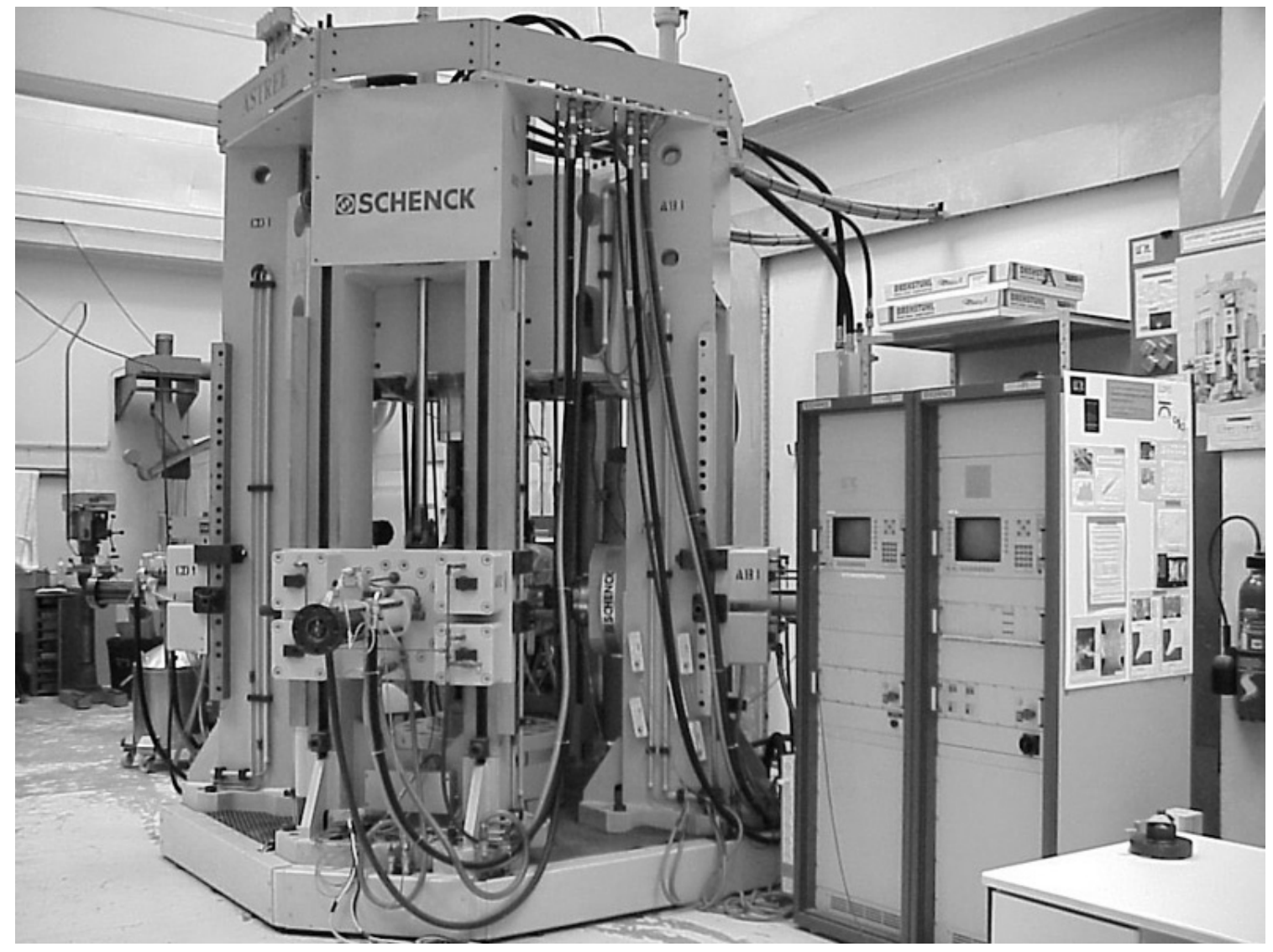

Figure 3. Doudard et al. 


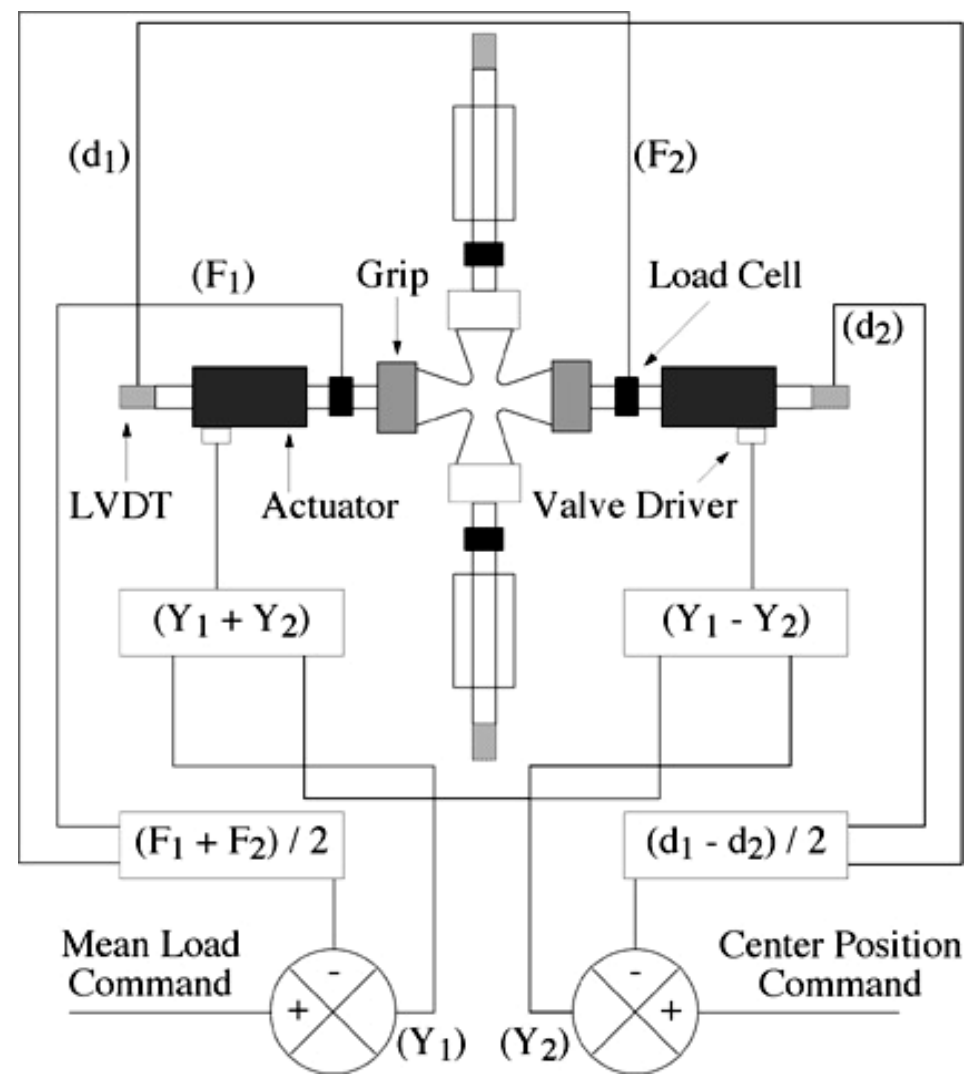

Figure 4. Doudard et al. 


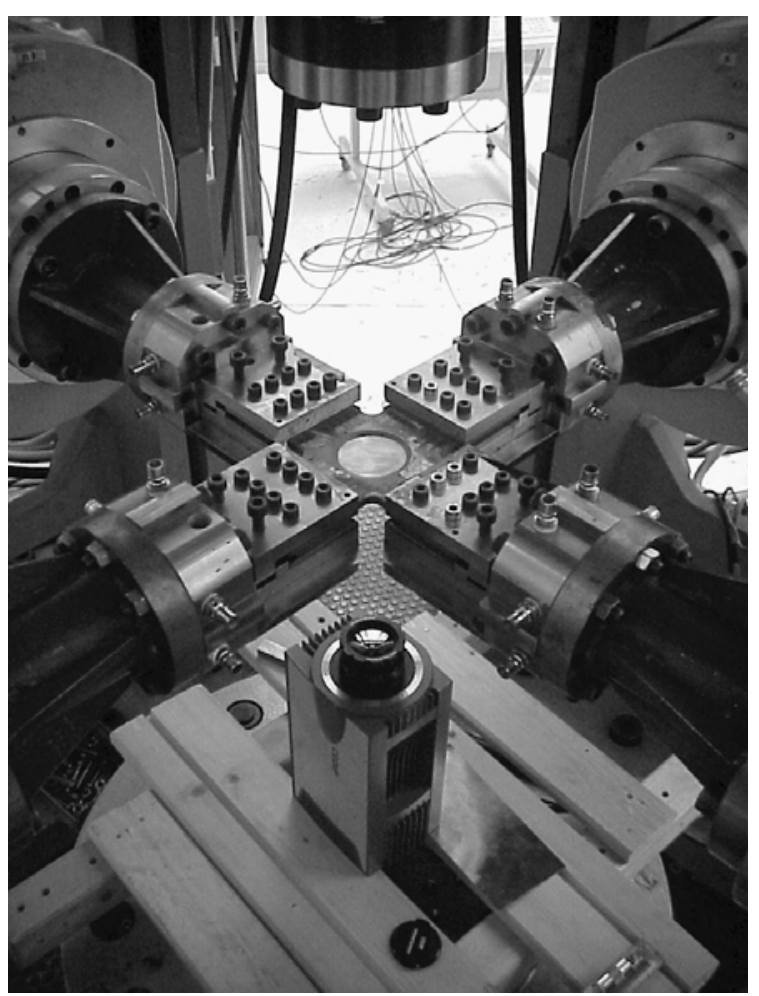

- a -
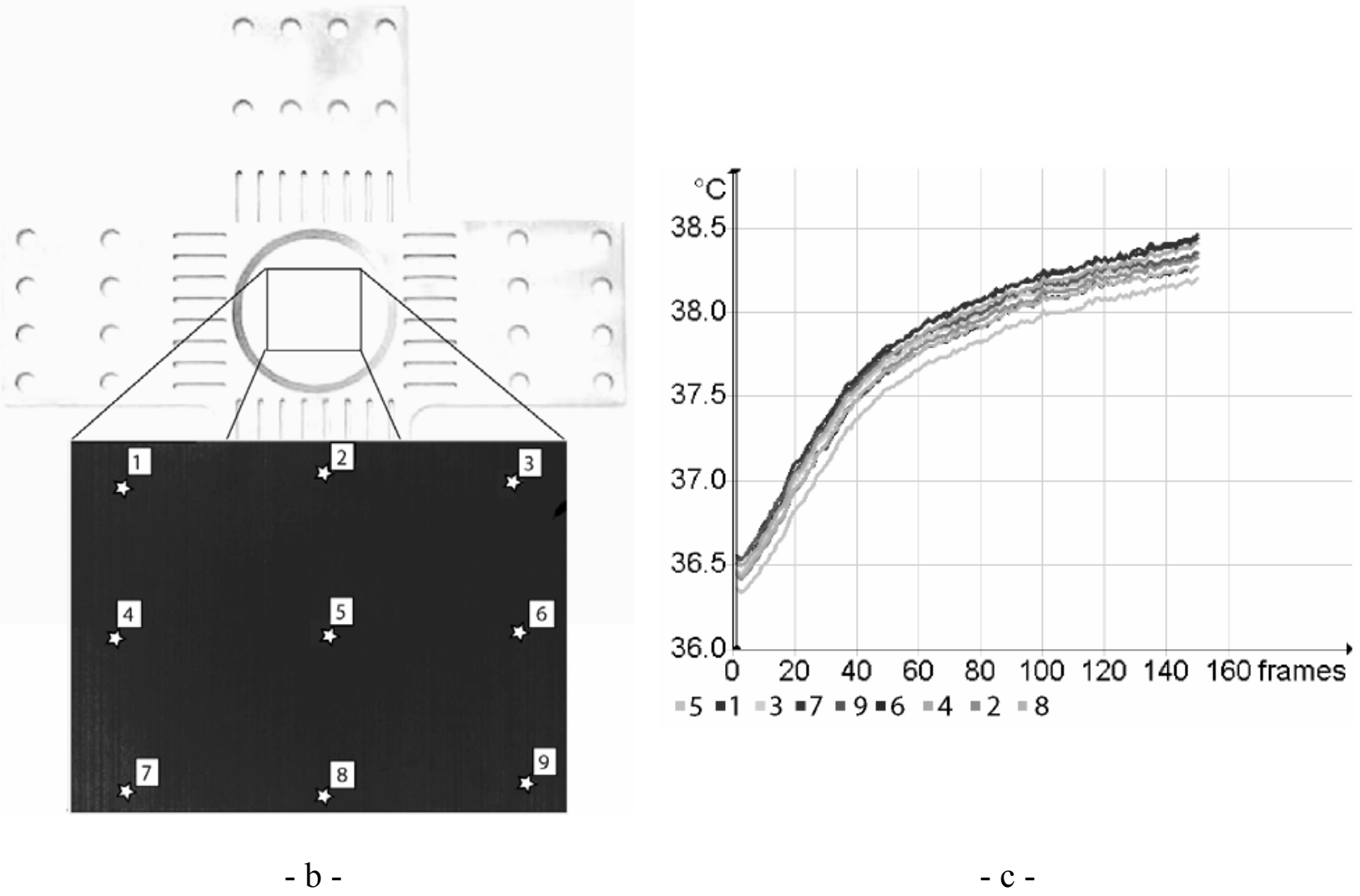

Figure 5. Doudard et al. 

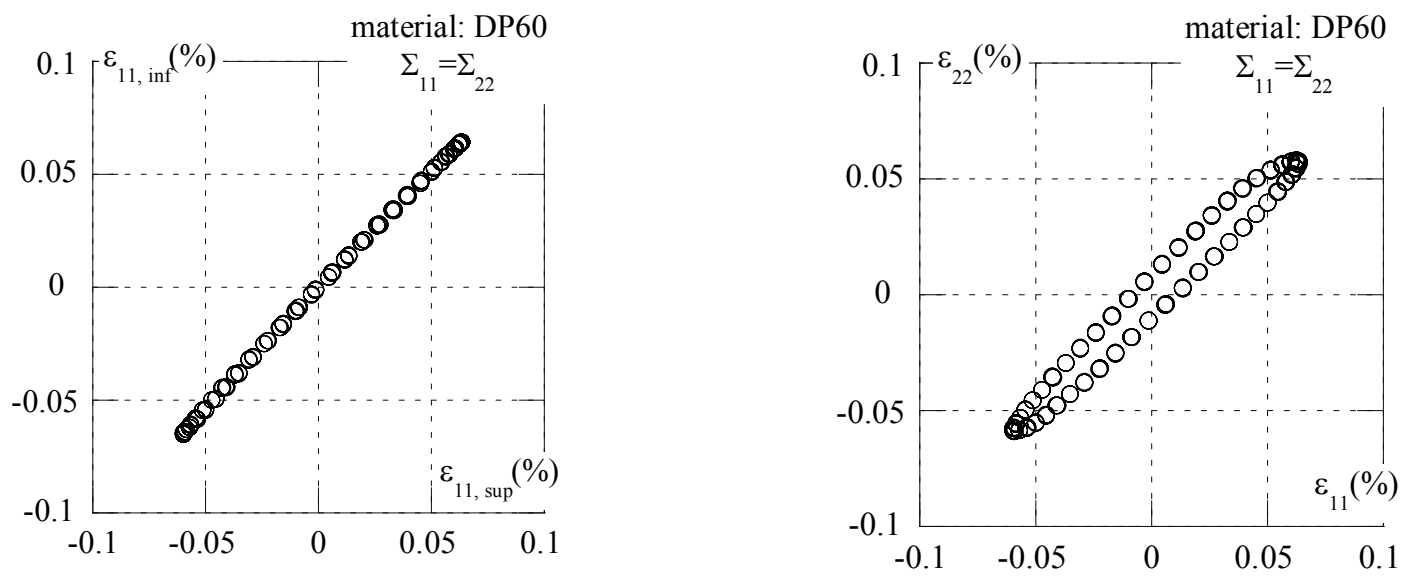

- a -

- b -

Figure 6. Doudard et al. 


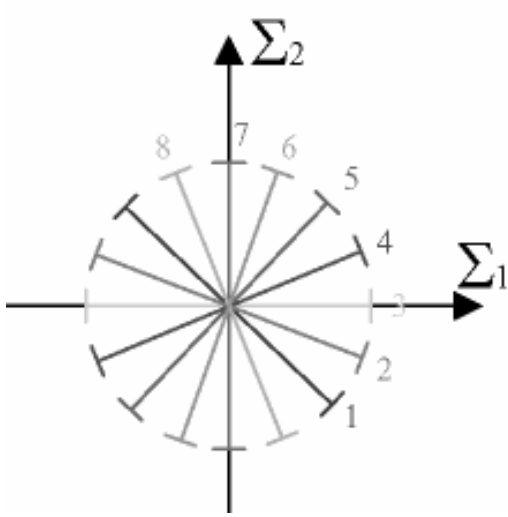

- a -

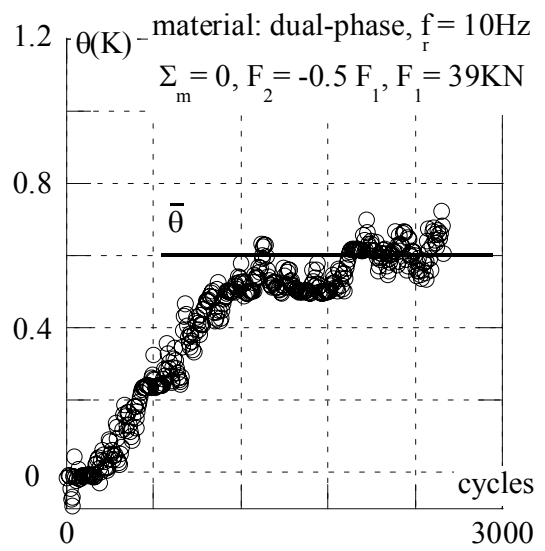

- C -

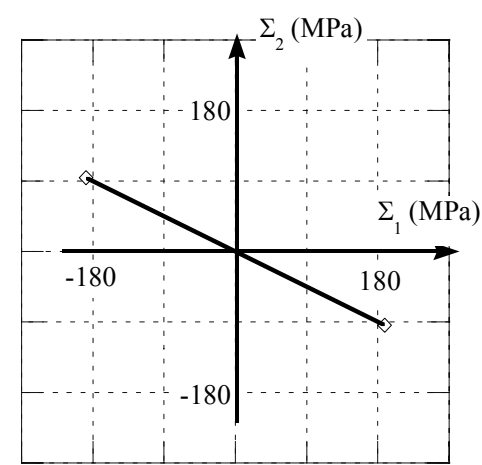

- e -

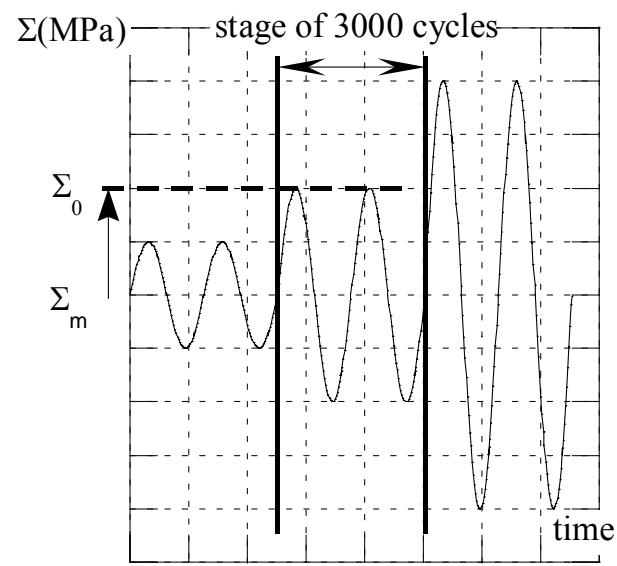

$-b-$

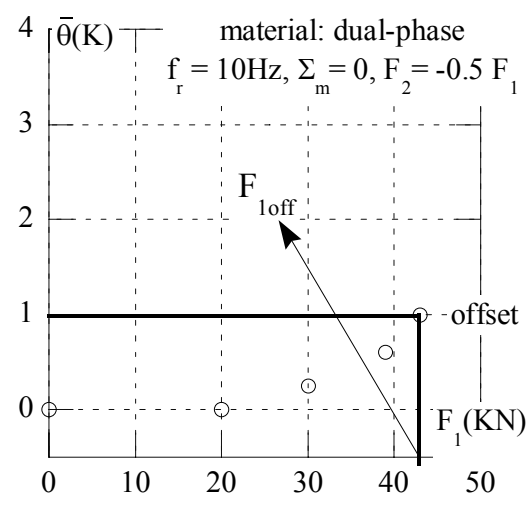

$-d-$

Figure 7. Doudard et al. 


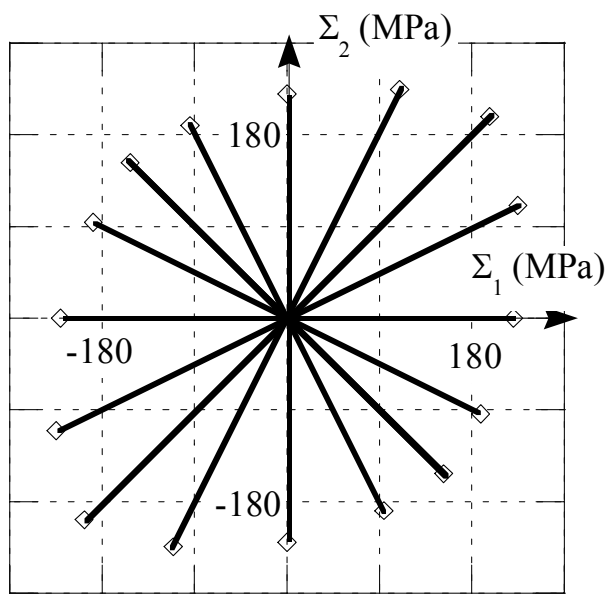

Figure 8. Doudard et al. 

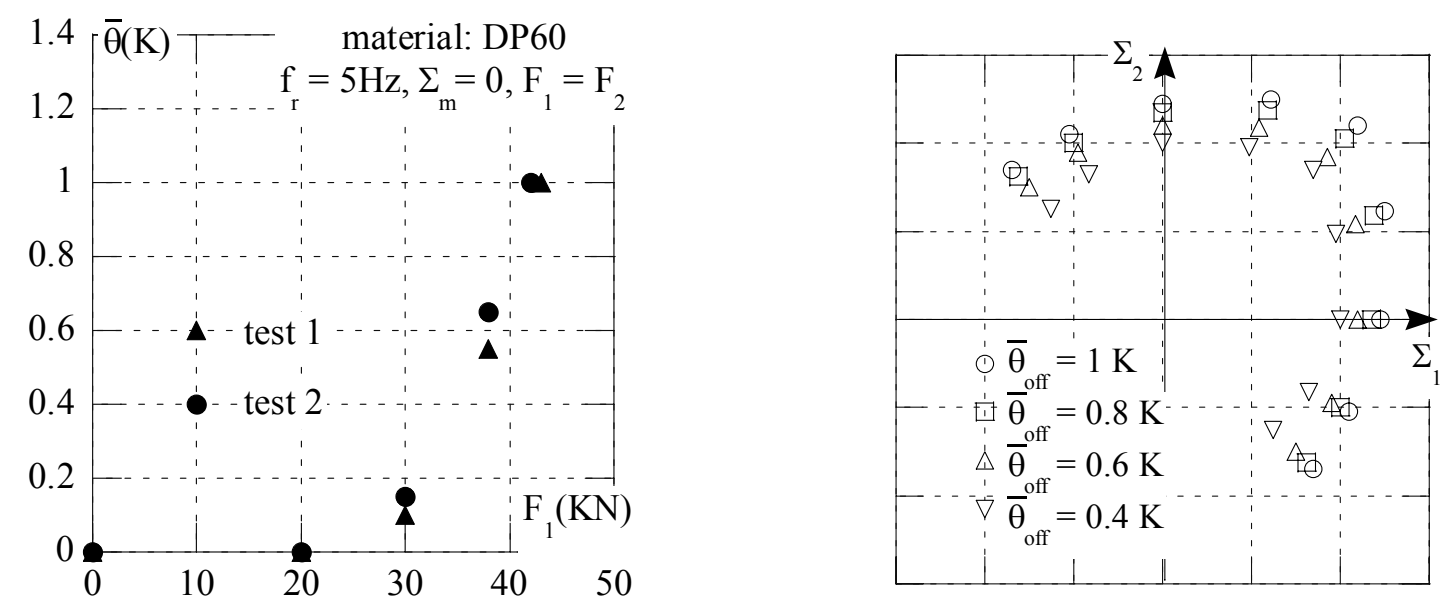

- a -

$-b-$

Figure 9. Doudard et al. 

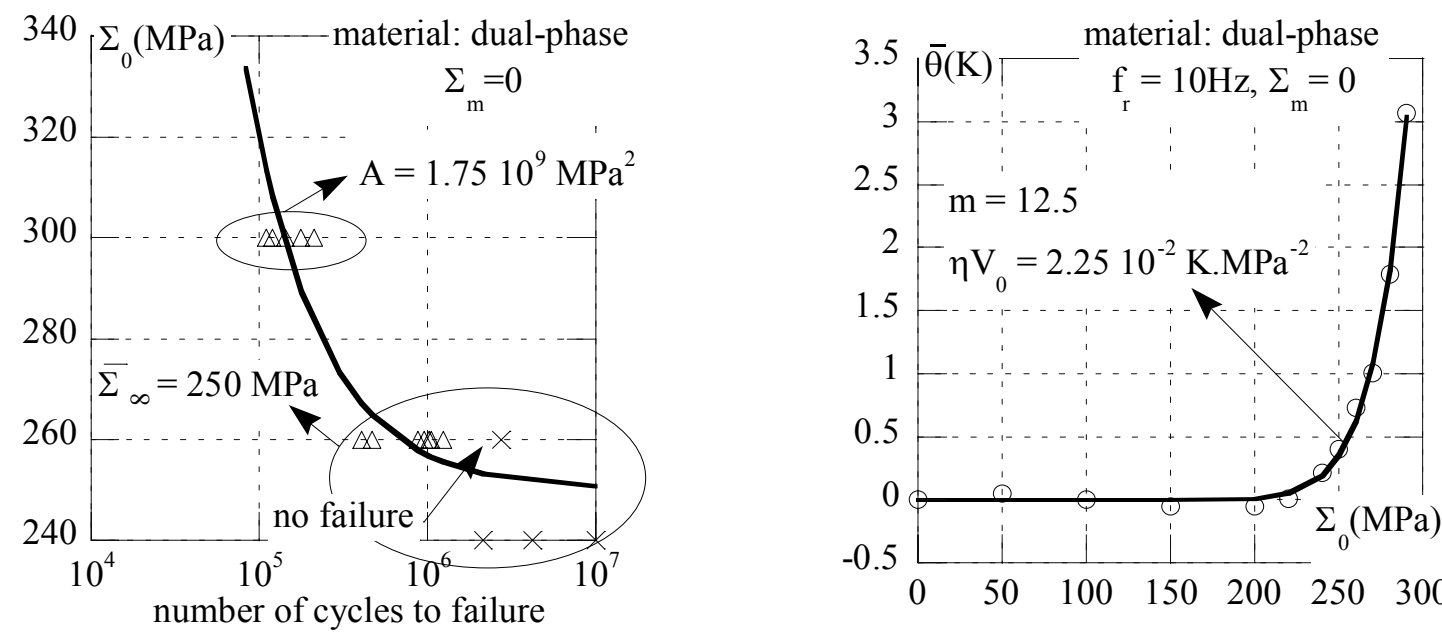

- a -

$-b-$

Figure 10. Doudard et al. 


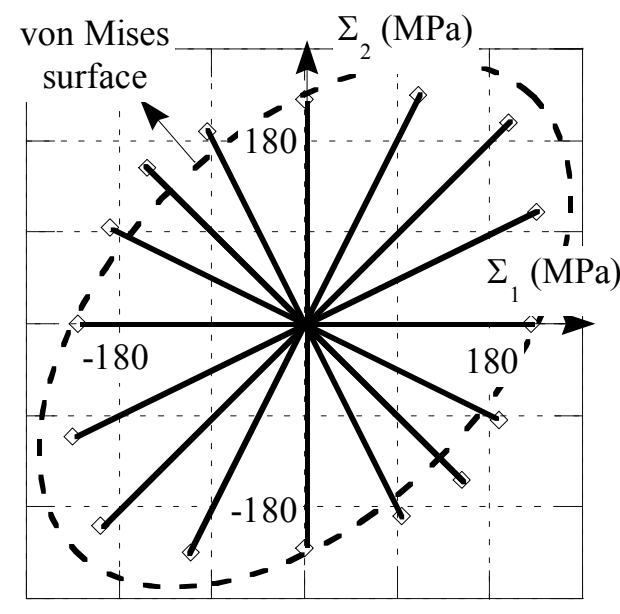

- a -

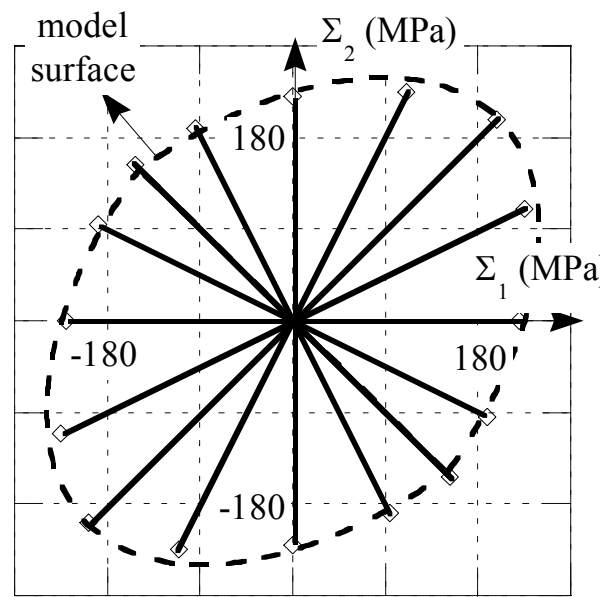

$-b-$

Figure 11. Doudard et al. 


\section{List of tables}

Table 1: Chemical composition of the studied DP60 steel $\left(10^{-3} \mathrm{wt} \%\right)$

Table 2: Mechanical properties of the DP60 steel $(\mathrm{Ys}=$ Yield stress, UTS $=$ Ultimate Tensile Strength, $\mathrm{El}=$ Elongation at failure) . 
Table 1. Doudard et al.

\begin{tabular}{c|c|c|c|c|c|c}
\hline $\mathrm{C}$ & $\mathrm{Mn}$ & $\mathrm{Si}$ & $\mathrm{Cr}$ & $\mathrm{Ti}$ & $\mathrm{S}$ & $\mathrm{Fe}$ \\
\hline 90 & 1000 & 250 & 200 & 10 & $<5$ & Balance \\
\hline
\end{tabular}

Table 2. Doudard et al.

\begin{tabular}{c|c|c|c}
\hline Ys & UTS & Ys / UTS & El \\
\hline$>300 \mathrm{MPa}$ & $>600 \mathrm{MPa}$ & $<0.6$ & $25 \%$ \\
\hline
\end{tabular}

